\title{
AQUI SE DIZ CARAPANÃ! VARIAÇÃO LINGUÍSTICA, IDENTIDADE E HUMOR NAS AULAS DE ESTUDOS PARAENSES EM TEMPO DE PANDEMIA
}

\author{
HERE IT SAYS CARAPANÃ! LINGUISTIC VARIATION, IDENTITY AND \\ HUMOR IN THE VIDEO ESTUDOS PARAENSES IN PANDEMIC TIME
}

\author{
Davi Pereira de Souza ${ }^{1}$ \\ http://lattes.cnpq.br/6471884540261468 \\ Carlene Ferreira Nunes Salvador ${ }^{2}$ \\ http://lattes.cnpq.br/0221348031478049 \\ https://orcid.org/0000-0001-9403-1227
}

Enviado em: 30/09/2020

Aceito em: 10/10/2020

\begin{abstract}
RESUMO: O objetivo deste artigo consiste em identificar a ocorrência de variação linguística no vídeo Estudos Paraenses, do humorista belenense Bob Flly, certificando se as variantes observadas já foram registradas em trabalhos acadêmicos geolinguísticos produzidos com dados da região Norte do Brasil, com o intuito de verificar como essa variação linguística está associada à construção da identidade dos indivíduos e ao humor produzido como decorrência dessa relação. Para tanto, o aporte teórico adotado está circunscrito a Labov (2008 [1972]), Weinreich, Labov e Herzog (2006 [1968]) e Cardoso (2010) no que diz respeito à variação linguística, a Rajagopalan (1998) em razão do tratamento dado à questão da identidade e a Possenti (1998) em referência ao viés humorístico presente nas facetas da língua. Do ponto de vista metodológico, a pesquisa segue a proposta de um estudo de caso conforme Yin (2018), por tratar-se de um fenômeno contemporâneo, cuja amostra foi extraída da fala dos personagens presentes no vídeo Estudos Paraenses, postado na plataforma Youtube no Canal Pavulagem do internauta Bob Flly. Os resultados apontam variação em nível lexical, como por exemplo, lagartixa $>$ osga, libélula $>$ jacinta, mosquito $>$ carapanã, lowva-a-deus $>$ punhamesa; fonética, como em $p[0]$ nhamesa $>p[u]$ nhamesa; e semântica, observada em perereca, com os sentidos relacionados à rã e referente à vulva.
\end{abstract}

Palavras-chave: Variação linguística. Identidade. Humor. Vídeo Youtube. Bob Flly.

ABSTRACT: The objective of this article is to identify the occurrence of linguistic variation in the video Estudos Paraenses, by the belenense humorist Bob Flly, certifying that the observed variations have already been recorded in academic variation geolinguistic produced with data from the North of Brazil, in order to verify how this linguistic variation is associated with the construction of the individuals' identity and the humor produced as a consequence this relationship. For this purpose, the theoretical contribution adopted is limited to Labov (1980 [1972]), Weinreich, Labov and Herzog (2006 [1968]) and Cardoso (2010) with regard to linguistic variation, Rajagopalan (1998) due to the treatment given to the identity and Possenti (1998) in reference to the humoristic facets of the language. From a methodological point of view, the

1. Graduado em Licenciatura em Letras (Habilitação em Língua Portuguesa); Mestre em Linguística; Doutorando em estudos linguísticos na Universidade Federal do Pará. Professor substituto da Universidade do Estado do Pará e professor de Língua Portuguesa na Secretaria de Educação do Pará (SEDUC).

2 Graduada em Licenciatura Plena em Língua Inglesa pela Universidade Federal do Pará (2004); graduada em Licenciatura Plena em Letras - Língua Portuguesa pela Universidade Federal do Pará (2002); mestra em Letras: Linguística e Teoria Literária pela Universidade Federal do Pará (2006) e doutora em Letras: Linguística e Teoria Literária pela Universidade Federal do Pará (2017). Docente do Curso de Letras - Língua Portuguesa da Universidade Federal Rural da Amazônia - UFRA. 
research follows the proposal of a case study according to Yin (2018), as it is a contemporary phenomenon, whose sample was extracted from the speech of the characters in the video Estudos Paraenses, posted on the Youtube platform at Channel Pavulagem by internet user Bob Flly. The results indicate variation at the lexical level, such as, for example, lagartixa $>$ osga, libélula $>$ jacinta, mosquito $>$ carapanã, lowva-a-deus $>$ punbamesa; $p[0]$ nhamesa $>\mathrm{p}[\mathrm{u}]$ nhamesa and semantics, observed in frog, with the senses related to the frog and referring to the vulva.

Keywords: Linguistic variation. Identity. Humor. Youtube vídeo. Bob Flly.

\section{INTRODUÇÃO}

As línguas naturais sofrem variação desde o nível fonético até o nível discursivo. As nuances dessa variação se materializam em falas que se particularizam como um modo de expressar de uma dada comunidade. Determinada por condicionadores que influenciam em nível intralinguístico (fonético, morfológico, sintático e semântico), a variação linguística também mostra sua faceta a partir de elementos exteriores à língua ou extralinguísticos, tais como fatores de ordem social (diastrática), histórica (diacrônica), estilística (diafásica) e a que nos interessa nesse artigo, a regional (diatópica).

A variação diatópica, aquela que ocorre em face da distribuição espacial dos falantes, revela em muitos contextos discursivos as marcas particulares de um país, de uma região, de um estado, de um município e das comunidades deste município. Nesse contexto geográfico, a região amazônica, na maioria das vezes lembrada apenas por sua extensão territorial, além da diversidade de sua fauna e de sua flora, também apresenta variedade linguística que a caracteriza.

Os falares do povo amazônida também apresentam traços singulares, como variações em nível fonético, dentre as quais o fenômeno do alçamento das vogais muito característico na fala dos moradores de Cametá na mesorregião do nordeste paraense, o qual se verifica também em Abaetetuba e Moju, outros municípios do estado do Pará; não se pode deixar de mencionar também a realização do fonema lateral palatal $/ K /$ na região sudeste paraense, onde a influência migratória de povos vindos de diversos estados da federação (Maranhão, Ceará, Espírito Santo, Minas Gerais e outros) contribuiu sobremaneira para uma realização mais palatalizada desse fonema; além desses casos, é importante salientar a alta produção do termo égua, o qual talvez não seja o traço mais característico do falante belenense, mas com certeza é a marca lexical mais conhecida do falar paraense por sujeitos de outras localidades da federação brasileira.

Como visto, a variação linguística serve de aporte para a manifestação de especificidades dos diversos falares. Nesse sentido, ela também possibilita ao falante o reconhecimento de sua própria variedade linguística frente às manifestações de outros grupos de usuários da mesma língua. Esse processo, imbricado em aspectos culturais, evidencia a noção de identidade construída ao longo da vida.

Reconhecer-se como parte de uma comunidade, compartilhar rituais e comportamentos diários está além de uma prática isolada. Essa relação de inserção no mundo social é mediada pela linguagem, pela sensação de pertencimento e, hoje, pela internet. Atentos a esse movimento, verificamos na fala dos personagens do vídeo Estudos paraenses, publicado pelo internauta Bob Flly, um paraense de Belém, no Canal Pavulagem ancorado na plataforma Youtube, a noção de identidade construída a partir de suas falas regionalizadas e permeadas de humor. Assim, a partir do vídeo mencionado, verificamos a variação linguística sobretudo em nível lexical, em que os personagens, tendo por base uma atividade de escrita, ao mesmo tempo que divergem sobre a nomeação dos animais desenhados na folha de atividade, tentam embutir a sua variante lexical.

Ainda em relação ao vídeo, o personagem Bob Flly demonstra em trechos diferentes a sua filiação ao falar paraense, chegando a ser enfático, por vezes, o que demonstra além do aspecto diatópico a menção à identidade que ele deseja construir e repassar ao filho naquele contexto.

Ao observarmos essa relação estabelecida pelo youtuber paraense, propomos a escrita deste artigo com o objetivo de avaliar como a variação linguística influencia na noção de construção da 
identidade dos indivíduos, neste caso, a partir de uma faceta muito utilizada nos discursos, o humor, assim como estabelecemos a relação entre o vídeo e trabalhos de cunho acadêmico sobre variação linguística.

Propomos como organização principal do artigo uma seção que trata da Sociolinguística e suas questões epistemológicas; uma seção sobre o mundo virtual e aspectos referentes à construção da identidade; uma seção metodológica, a qual explicita a forma como a amostra foi constituída além da seção de apresentação dos resultados alcançados.

\section{SOCIOLINGUÍSTICA E VARIAÇÃO}

Como parte da dinâmica das línguas naturais, os fenômenos de variação e mudança linguísticas sempre existiram no uso, antes mesmo de serem considerados objetos de estudos de disciplinas específicas, como a Dialetologia, a Linguística histórica e a Sociolinguística. Obviamente, no quadro teórico de cada uma dessas e de outras disciplinas afins ou de vertentes sociolinguísticas, tanto a variação quanto a mudança não são recebem exatamente o mesmo tratamento teóricometodológico, divergindo em pontos de vista.

Surgida no final dos anos de 1950 e 1960, especialmente a partir dos trabalhos do linguista William Labov ${ }^{3}$ sobre o inglês não-padrão norte-americano, a Sociolinguística pode ser entendida tanto como uma disciplina linguística quanto como um programa teórico-metodológico que se fundamenta na indissociável relação entre língua e sociedade, sendo a fala o lugar desse encontro no qual a heterogeneidade dos fatos linguísticos é inerente ao sistema mais geral da língua, e não um comportamento assistemático.

De acordo com Lucchesi (2015):

os fundamentos do programa de pesquisa da Sociolinguística derivam da assunção de que é possível desenvolver um estudo empírico consistente da mudança linguística por meio da análise sistemática dos processos de variação observados em um dado momento na língua (LUCCHESI, 2015, p. 31).

$\mathrm{Na}$ origem dessa relação está a compreensão de um modelo de língua que alcança o uso variável do sistema e seus condicionantes de caráter social e estilístico (WEINREICH; LABOV; HERZOG, (2006 [1968]). Na visão desses autores, esse modelo contribui para um aprofundamento descritivo da competência linguística e para uma teoria da mudança que supera os desafios e os "estéreis paradoxos contra os quais a linguística histórica vem lutando há mais de um século" (WEINREICH; LABOV; HERZOG, 2006 [1968], p. 34).

Por outro lado, a Sociolinguística é frequentemente considerada uma subárea da Linguística, situada num espaço interdisciplinar, voltada para o estudo da língua em uso no interior das comunidades de fala (MOLLICA, 2015). Esse campo de estudo concebe a sociedade humana em termos de padrões e comportamentos relacionados, dentre os quais os linguísticos (SPOLSKY, 1998).

Nesse sentido, Guy (2012, p. 44) explica que a Sociolinguística tem como foco "as diferenças que encontramos entre falantes de camadas sociais distintas do mesmo lugar, e até as diferenças no uso de indivíduos em ocasiões distintas, com ouvintes diferentes, ou para fins diferentes". Seu objeto de estudo, portanto, é a língua em uso, em situação real de interação social, na qual se manifestam naturalmente distintos processos de variação linguística que podem indicar mudança concluída, em progresso ou variação estável, assumindo-se, como princípio, que a variação é inerente à língua.

Conforme ressalta Alkmin (2012), o nascimento da Sociolinguística é marcado por uma origem interdisciplinar. Além da vertente variacionista, tributada a Labov, há outras, como a etnográ-

\footnotetext{
3 Labov é considerado o "pai" da Sociolinguística, sendo particularmente responsável pela vertente conhecida como sociolinguística variacionista, sociolinguística laboviana ou teoria da variação.
} 
fica, interacional e a chamada sociolinguística educacional (BORTONI-RICARDO, 2014). Todavia, neste artigo, além da fundamentação geolingüística, foram adotados os pressupostos da teoria da variação, a qual foi a vertente que mais se desenvolveu no Brasil, particularmente nos estudos sociolinguísticos e geolinguísticos realizados na região Norte, no âmbito do projeto de pesquisa Geossociolinguística e Terminologia - GeoLinTerm (RAZKY; OLIVEIRA; LIMA, 2010).

A perspectiva Geossociolinguística (RAZKY, 1997; 1998), marca da maioria dos trabalhos geolinguísticos desenvolvidos no âmbito do GeoLinTerm, integra princípios e métodos da Sociolinguística à pesquisa de natureza geolinguística, assumindo a perspectiva pluridimensional para os fatos heterogêneos da língua. Com isso, busca-se ampliar o alcance explicativo da teoria, fornecendo análises que tratam da variação linguística "sustentada num tripé de fatores condicionantes: o espacial, o social e o linguístico" (LIMA; RAZKY; OLIVEIRA, 2020, p. 15, grifos dos autores), sem menosprezar a perspectiva temporal.

Nesse sentido, os estudos sociolinguísticos permitem, dentre outros fatores, o registro da variação que ocorre nas línguas, além de aferir como as pressões externas se manifestam nos diversos estratos sociais, inclusive em gêneros que circulam em ambiente virtual, como é o caso do vídeo aqui analisado.

\section{MUNDO VIRTUAL, IDENTIDADE E HUMOR}

As relações humanas foram alteradas sobremaneira desde a chegada da internet. Inicialmente um mercado preocupado com a venda e distribuição de hardwares, aos poucos, o mundo tecnológico foi ganhando outras configurações, sobretudo no desenvolvimento de softwares cada vez mais avançados e que nos últimos anos diminuiu a distância entre os habitantes do planeta. Sobre esse tema, Rajagopalan (1998, p. 43) salienta que "a identidade de um indivíduo se constrói na língua e através dela". Nesse sentido, língua e indivíduo se cruzam em uma interrelação em que, assim como a língua sofre variação e em alguns casos também mudança, da mesma forma o homem não nasce pronto e acabado, ao contrário, ao longo de sua vida passa por transformações e fases de reconhecimento, tal qual ocorre nas línguas naturais.

Nesse cenário tecnológico, é possível também perceber conteúdos divulgados na internet que abordam questões linguísticas, algumas das quais mostram que estão além de simples postagens despretensiosas. Internautas ávidos por curtidas disputam a atenção de usuários de diferentes partes do globo. Nesse jogo cibernético, não importa que as postagens ou comentários estejam carregados de preconceito ou afins. Lévy (2011) alerta para o perigo das relações existentes em ambiente virtual, uma vez que é possível ocultar a verdadeira identidade de quem está do outro lado da tela.

No ano de 2020, em tempos de pandemia, com a imposição do período de quarentena como medida de contenção ao contato social, a internet tornou-se o elo entre os indivíduos. Com as pessoas dentro de suas casas, impedidas de circularem ou trabalharem normalmente, o recurso da internet se tornou fundamental. $\mathrm{O}$ tempo ocioso foi minimizado pelo acesso constante às redes sociais. Nesse contexto de indisponibilidade presencial, a disponibilidade virtual alargou-se. Como uma forma de fugir do problema sanitário em escala mundial em que nos encontramos ou simplesmente como uma distração, internautas puderam mostrar seus talentos em diversas plataformas e redes sociais disponíveis.

Nesse contexto específico, surge Bob Flly, produtor de conteúdo para canais de redes sociais, o qual viu sua vida e sua produção saírem do anonimato e fazer parte de muitos lares com suas tiradas humorísticas que sobretudo evocam a variedade linguística do falar paraense, especialmente a variedade de Belém. Baseado no senso comum e na noção de identidade construída ao longo de sua vida, esse youtuber passou a disseminar vídeos cujo foco têm sempre algum aspecto voltado para a cultura paraense, inclusive em nível linguístico, o que pode ser comprovado nos títulos escolhidos por ele para nomear cada postagem de seu canal, eis alguns exemplos: Manias de avó paraense, $A$ história do sheik e o paraense, 50 tons de cinza paraense, O náufrago paraense, Recrutando paraense para $3^{a}$ 
Guerra Mundial, Tradutor paraense (Fortaleza e Santa Catarina), dentre outros vídeos.

A aceitação dos vídeos de Bob Flly se dá em parte por seus conteúdos acionarem a memória coletiva, a conjunção de grupo. Nesse cenário, não é possível aferir o alcance das produções que circulam na internet nem tampouco mensurar como os indivíduos usam e compartilham conteúdos em aplicativos de mensagens com muita velocidade, porém, é necessário pensar nesse processo de forma crítica. Nas palavras de Rajagopalan (2003), a globalização é um:

[...] fator determinante tanto da reviravolta nos padrões tradicionais de conceituação da identidade e dos graus de "autenticidade" do falante como também das formas e usos de uma língua, quanto do renovado interesse pela questão das políticas linguísticas (RAJAGOPALAN, 2003, p. 41).

Para o autor, o mesmo processo de globalização que possibilita a diminuição das distâncias também arrola mudanças de ordem geral, inclusive aquelas relacionadas à linguagem. A construção da identidade, nesse contexto, aponta também para o fator de autenticidade presente em cada produção. No caso específico do vídeo assinalado, o fator relativo à autoria se mostra a partir das escolhas lexicais selecionadas para marcar os traços de origem paraense.

Nesse caso, são acionadas de uma única vez dois elementos particulares, a variação diatópica, pois há a clara referência ao falar das pessoas que são nativas do estado do Pará, além da variação lexical, manifestação que sinaliza o uso exclusivo de palavras utilizadas em solo paraense.

Além dos fatores listados, outro elemento constitui o conteúdo das publicações do digital influencer, o traço humorístico. Sobre o riso, Freud (1977 [1905]) destaca que:

O humor é próprio do ser humano, ou seja, só o homem pode rir e fazer o outro rir. Não há humor fora do ser humano; o rir é uma característica humana, é um fenômeno de descarga da excitação mental e uma prova de que o emprego psíquico dessa excitação tropeça repentinamente contra um obstáculo (FREUD, 1977 [1905], p. 170).

Nessas condições, o autor deixa claro que apenas os seres humanos podem acionar e produzir o riso, o humor. A atividade ressaltada por Freud (1977 [1905]) se realiza em parte pelo uso da linguagem, da palavra desvirtuada de seu sentido original.

Ainda em relação ao humor, de um lado, Bergson (1983) atenta para o fato de que o riso é consumado sempre de forma grupal, no qual determinados conjuntos de atitudes são descritos e postos como desvios perante uma comunidade. Por outro lado, Possenti (1998) salienta que o humor é acionado a partir de mecanismos linguísticos. As duas assertivas se complementam à medida que o uso da linguagem utilizada para a realização de um ato cômico ou humorístico sinaliza gestos sociais que violam uma conduta ideal, imaginária, os autores convergem, portanto, em suas deliberações.

Possenti (1998) atenta ainda para o fato de que, se a comunidade não compartilha os mesmos códigos linguísticos, o fator humorístico fica comprometido, pois se perde o controle da interpretação o qual reside exatamente no desvirtuamento do padrão. O humor então é factual, partilhado e consensual.

Em relação ao vídeo analisado neste artigo, o humor ocorre justamente nos momentos em que os personagens assumem o papel de defensores de uma variedade linguística que carrega em si singularidades. Se tomarmos o trecho em que o pai diz ao filho, "- perereca tem ainda outro sentido, mas você ainda é jovem para essa conversa", o indivíduo adulto pertencente a essa comunidade comunga da mesma informação e sabe, nesse caso, que 'perereca' se refere ao órgão típico de pessoas do sexo feminino. Nesse trecho do vídeo, além do fator linguístico corroborar o entendimento, há também a ajuda da sonoplastia que insere uma risada pontual, o que ajuda a marcar e ativar o tão esperado riso.

Além disso, não se pode descartar dentro desse processo a noção de identidade construída 
principalmente por meio das escolhas lexicais arroladas no vídeo. É provável que o produtor do conteúdo desconheça as investigações de cunho dialetal que já foram ou estão sendo realizadas acerca do uso de determinadas palavras utilizadas por ele no vídeo. Estudos realizados, alguns no âmbito do Projeto Atlas Linguístico do Brasil - ALiB (RAMOS; BEZERRA; ROCHA; REIS, 2010; AGUILERA, 2010; BARBOSA; ISQUERDO, 2017) comprovam a produtividade de tais variantes além de descrever a variação de alguns dos termos arrolados no vídeo, apresentam inclusive a cartografia, estão registrados em cartas linguísticas cujo objetivo reside em mapear os falares do povo brasileiro e registram variantes lexicais para os itens libélula, galinha d'angola e abóbora. Na seção de resultados apresentaremos o cruzamento de tais trabalhos com vista a estabelecer o panorama dessas produções no Brasil.

\section{METODOLOGIA}

Para a elaboração deste artigo seguimos a orientação de Yin (2018) no que concerne à pesquisa realizada com base em um estudo de caso. $\mathrm{O}$ autor define esse método como:

[...] o estudo de caso é uma investigação empírica que investiga um fenômeno contemporâneo em profundidade e em seu contexto de vida real, especialmente quando os limites entre o fenômeno e o contexto não são claramente evidentes (YIN, 2018, p. 39).

De acordo com o autor supramencionado, o estudo de caso, o qual pode ser dividido em três tipologias, quais sejam: descritiva, explanatória e exploratória, apresenta ainda características que o tornam uma opção metodológica cada vez mais utilizada por pesquisadores, uma vez que se define também em razão de sua especificidade, pluralidade, contemporaneidade e análise intensiva. Nestes termos, em face do objeto eleito para análise neste artigo, o vídeo Estudos Paraenses apresenta pelo menos dois fatores essenciais na composição do estudo de caso que aqui se propõe, a tipologia descritiva e a natureza contemporânea, o que ampara a pesquisa de cunho qualitativo.

Ademais, a pesquisa sociolinguística (TARALLO, 2007) também fornece ferramentas que possibilitam aferir quanti e qualitativamente como as pressões da língua atuam no sistema dessa língua, possibilitando o fenômeno da variação e da mudança linguística, em alguns casos.

Tendo em vista a difusão, o acesso e o compartilhamento de informações proporcionados pela internet, elegemos como amostra de análise o vídeo postado no Canal Pavulagem do internauta paraense Bob Flly, denominado Estudos Paraenses. O vídeo está ancorado na plataforma do Youtube, no link: https://www.youtube.com/watch?v=uxxEOsrU6Fs.

O vídeo sob análise foi postado no dia 01 de julho de 2020, data em que a população mundial sentia e ainda sente os efeitos do isolamento social ocasionado pela pandemia gerada pelo novo Sars-02, popularmente conhecido como Coronavírus (Covid-19), inclusive a classe estudantil que passou a realizar suas atividades escolares por meio de ensino remoto e tarefas escritas, nas quais os pais ou responsáveis passaram a exercer o mesmo papel de educadores e professores.

De acordo com informações coletadas do Youtube, o Canal Pavulagem foi criado no dia 15 de março de 2015 e atualmente dispõe de 187 mil inscritos, com mais de 13 milhões de visualizações. Dessas visualizações, até o dia de nossa consulta, 95.329 são originárias do vídeo Estudos Paraenses, com 8,4 mil marcações de 'gostei' e 55 'não gostei'. O tempo total de reprodução do vídeo é de $03 \mathrm{~m} 04 \mathrm{~s}$.

Após selecionarmos o vídeo, passamos a verificar quais palavras compunham a atividade que dera origem ao assunto mote. Desse modo, a lista da atividade de Ciências é encabeçada pela imagem de seis animais, os quais recebem diferentes denominações nos estados brasileiros. Há ainda, a menção a outra lista baseada em nome de alimentos, porém, nesse caso, só é explorada uma palavra.

$\mathrm{Na}$ etapa seguinte, verificamos em aporte sociolinguístico qual o tratamento dado às variantes listadas no vídeo de modo que pudéssemos atribuir o caráter científico na abordagem de um 
dado contemporâneo e usual, subsidiado pela internet e por ela difundido. Um caminho que permite a um falante do Norte do país levar a sua variante ao conhecimento de um falante localizado na região Sul do país, e vice-versa.

\section{APRESENTAÇÃO DOS RESULTADOS}

A observação da variação existente no vídeo de Bob Flly (2020) nos levou aos resultados dispostos no Quadro 1.

\begin{tabular}{|c|c|c|}
\hline \multirow{6}{*}{ Variação lexical } & Resposta Esperada & Resposta obtida \\
\hline & rã/perereca & jia/perereca \\
\hline & lagartixa & osga \\
\hline & libélula & jacinta, cambito, lava cu \\
\hline & mosquito $^{4}$ & carapanã \\
\hline & louva-a-deus & punha mesa \\
\hline \multirow{3}{*}{ Variação fonética } & $\mathrm{p}[\mathrm{o}]$ nha mesa & $\mathrm{p}[\mathrm{u}]$ nha mesa \\
\hline & $\mathrm{m}[\mathrm{o}]$ squit $[\mathrm{o}]$ & $\mathrm{m}[\mathrm{u}]$ squit $[\mathrm{u}]$ \\
\hline & lagartixa & largatixa \\
\hline Variação semântica & $\begin{array}{l}\text { "- Perereca pra cá é outra coisa, mas tu tá muito } \\
\text { jovem pra essa conversa" (risos) }(02: 27-32)\end{array}$ & $\begin{array}{l}\text { - acepção 1: variante de jia } \\
\text {-acepção 2: vulva }\end{array}$ \\
\hline
\end{tabular}

Fonte: Elaboração dos autores.

O levantamento das variantes relacionadas no Quadro 1 aponta três tipologias. Variação em nível lexical, em que os personagens colocam em oposição a denominação dos animais, como, por exemplo, em lagartixa > osga; variação fonética, nos dois casos arrolados, vemos o fenômeno do alçamento dos segmentos vocálicos em que a vogal média [o] é realizada como vogal alta posterior $[\mathrm{u}]$ independentemente da posição que se encontra, tônica ou pretônica; variação semântica: "Perereca pra cá é outra coisa, mas tu tá muito jovem pra essa conversa" (risos) (02:27-02:32), em que claramente o personagem mais maduro aciona a competência de uso do termo 'perereca', mas que não é entendido pela criança, uma vez que se trata de uma tema comum entre indivíduos de idade mais avançada.

Como vimos nos dados expressos no Quadro 1, o personagem mais adulto do vídeo aciona palavras que ele considera como marcas do falar paraense, baseado principalmente em sua experiência de vida e compartilhamento de tais vocábulos dentro de sua própria comunidade. Em seu discurso, percebe-se a noção da identidade construída, nuances de prosódia e encaixamento de falas tipicamente paraenses, as quais devem ser provavelmente pronunciadas como uma forma de chamar a atenção de quem vai consumir aquele produto audiovisual. Após breve consulta a dicionários gerais da língua portuguesa, verificamos que, das doze lexias observadas no vídeo, apenas ponhamesa não possui registro nos referidos repertórios, aparecendo apenas sob a forma variante põe mesa, no dicionário Houaiss (2009), conforme demonstrado no Quadro 2.

Quadro 2 - Consulta a dicionários de língua geral

\begin{tabular}{|l|c|c|c|c|c|}
\hline \multicolumn{1}{|c|}{ Item lexical } & Michaelis online & Houaiss (2009) & Item lexical & Michaelis online & Houaiss (2009) \\
\hline cambito & $\mathrm{X}$ & $\mathrm{X}$ & libélula & $\mathrm{X}$ & $\mathrm{X}$ \\
\hline carapanã & $\mathrm{X}$ & $\mathrm{X}$ & louva-a-deus & $\mathrm{X}$ & $\mathrm{X}$ \\
\hline jacinta & $\mathrm{X}$ & $\mathrm{X}$ & mosquito & $\mathrm{X}$ & $\mathrm{X}$ \\
\hline Jia & $\mathrm{X}$ & $\mathrm{X}$ & osga & $\mathrm{X}$ & $\mathrm{X}$ \\
\hline lagartixa & $\mathrm{X}$ & $\mathrm{X}$ & perereca & $\mathrm{X}$ & $\mathrm{X}$ \\
\hline lava cu & $\mathrm{X}$ & $\mathrm{X}$ & ponhamesa & sem registro & põe mesa \\
\hline
\end{tabular}

Fonte: Elaborado pelos autores.

4 Essa variante é a que está registrada no produto que aparece no vídeo, sendo justificada pelo próprio personagem como “...isso é feito lá po Sul” (1:13-1:15). 
Em relação ao primeiro animal listado na atividade, o qual apresenta logo depois da imagem nove espaços que deveriam ser preenchidos com a variante lagartixa, o personagem-pai, baseado em sua própria experiência linguística, assume tratar-se de osga. Em nosso levantamento, encontramos a dissertação de Guedes (2012), que registra a variante osga como a mais frequente entre nove outras variantes encontradas no estudo feito em 12 cidades não-capitais do estado do Pará (Santarém, Oriximiná, Anajás, Breves, Castanhal, Santo Antônio do Tauá, Abaetetuba, Bragança, Altamira, Itaituba, Conceição do Araguaia e Redenção).

No caso da segunda unidade, para a qual se espera a resposta libélula, Kevenzinho respondeu prontamente com essa variante, mas logo foi corrigido por seu pai, que lhe disse: "Ora libélula! O nome disso é jacinta, rapá!", anunciando que, a depender da região, esse mesmo animal é conhecido como lava-cu e cambito. De fato, encontramos estudos que atestam o uso dessas variantes no Pará, com predominância da forma jacinta. Silva (2002), por exemplo, registrou a presença majoritária dessa variante na Mesorregião do Marajó/PA; Guedes (2012), por sua vez, demonstrou uma tendência de uso dessa lexia nas mesorregiões paraenses Baixo Amazonas, Sudoeste, Marajó, Metropolitana e Nordeste; Sá (2013) verificou 55\% das ocorrências para o item jacinta relativas ao distrito de Mosqueiro/PA; Barros (2017) também a registrou na cidade de Santarém/PA; e Costa e Silva (2018) a encontraram como variante preferencial na fala de moradores do município de IgarapéMiri/PA. Esses resultados confirmam a produtividade dessa unidade no Estado.

Ainda sobre essa variante citada no vídeo, Aguilera (2010) apresenta um panorama da distribuição nas capitais brasileiras, em referência à Questão 85 - ... o inseto de corpo comprido e fino, com quatro asas bem transparentes, que voa e bate a parte traseira na água?, do Questionário Semântico-lexical - QSL, do ALiB, cuja resposta esperada é libélula. Aguilera (2010) aponta 18 variantes nas capitais brasileiras, porém, o estudo não menciona nenhuma ocorrência na capital do Pará, Belém. Contudo, em estudo posterior (CARDOSO et al., 2014b), nas primeiras cartas publicadas do ALiB, essa variante está registrada na carta L12 do ALiB (CARDOSO et al., 2014) confirmando a fala do personagem-pai no vídeo Estudos Paraenses, pois ela evidencia que, em Belém, a variante mais frequente foi jacinta, tal qual ele afirma ao personagem Kevinho. Segundo Aguilera et al. (2016), a variante jacinta se estende para todas as capitais do Norte do Brasil.

Em relação às demais variantes proferidas por Bob, lava-cu e cambito, Guedes (2012) atestou a preferência de cambito na mesorregião sudeste, no Pará, ao passo que Ramos, Bezerra, Rocha e Reis (2012) a registraram como uma das variantes mais frequentes do estado do Maranhão. Já a variante lava-cu foi observada na região Centro-Oeste, no estudo relativo às capitais (AGUILERA et al., 2016) e nos dados do Atlas Linguístico de Pernambuco (SÁ, 2014).

Nesse cenário, podemos dizer que a defesa do personagem Bob em relação à preferência da variante jacinta faz sentido, em função da frequência de uso e de constituir parte da sua identidade linguístico-cultural, ainda que ele (Bob Flly) não tenha acesso a essa documentação linguística, o que pode justificar o fato de ele desconhecer que jacinta não é exclusividade do Pará.

Com vistas a estabelecer a validação dos dados, voltamos ao Canal Pavulagem para verificar na aba 'comentários' a reação de alguns inscritos no canal. Vejamos algumas das respostas encontradas dispostas na Figura 1. 
Figura 1 - Comentários dos internautas

\section{A Abutre Vale do Jari 4 semanas atrás Jacinta \\ It 2 \&I RESPONDER \\ Leninha Santos

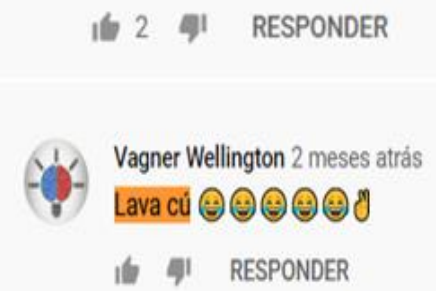 \\ ,

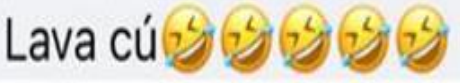

(ISSN 2238-8060)

Fonte: https:/ /www.youtube.com/watch?v=uxxEOsrU6Fs. Acesso em 19/09/2020

Os comentários dos internautas que visualizam o vídeo comprovam o efeito jocoso que a fala dos personagens provoca, confirmando a premissa de Bergson (1983) de que o riso é uma manifestação grupal. Algumas vezes, os usuários completam a opinião expressa por meio de emojis ou onomatopeias que dão ênfase ao que foi escrito.

Outro item citado no vídeo se refere à Questão 67 - ... a ave de criação parecida com a galinha, de penas pretas com pintinhas brancas? cujas respostas esperadas são galinha d'angola/guiné/ cocar. Em sua aula, porém, o personagem Bob afirma que, no Pará, se diz picota. Acerca dessa afirmação, verificamos o comportamento dos estudos dialetológicos em busca de registros referentes a essa unidade lexical.

O estudo apresentado por Ramos, Bezerra, Rocha e Reis (2012) registra as variantes para galinha d'angola com base em dados extraídos da fala de informantes do Maranhão. Nesse estudo, não há referência a picota, mesmo sendo o Maranhão um estado fronteiriço ao Pará. Há, porém, registro dessa variante na Carta L11 do ALiB (CARDOSO et al., 2014).

Assim como ocorreu com o item jacinta, o termo picota também está registrado nas ocorrências de Belém, mas no caso em questão há também a menção à galinha d'angola, porém este último com apenas $25 \%$ de produtividade em relação à picota. Essa carta confirma as conclusões de Cardoso e Mota (2012) que, ao analisarem a distribuição das variantes para essa questão nas capitais brasileiras, já observavam a predominância da variante picote na região Norte do país, com exceção de Rio Branco (CARDOSO et al., 2014). Da mesma forma, Guedes (2012) identificou picota como a variante mais frequente nas mesorregiões paraenses Nordeste, Marajó e Baixo Amazonas. Desse modo, mais uma vez, a fala do personagem Bob é corroborada pelos dados de pesquisadores da área.

Em continuidade em busca de estudos científicos, encontramos também a variante que encabeça o título de nosso artigo referente à Questão 88 - ... aquele inseto pequeno, de perninhas compridas, que canta no ouvido das pessoas de noite? Nesse caso, a resposta esperada seria pernilongo/mosquito, porém o personagem-pai, no contexto da aula, é enfático ao afirmar que, no Pará, se diz carapanã. Essa assertiva é cientificamente comprovada, uma vez que, no estudo de Costa e Isquerdo (2010), baseado na variação diatópica dessa variante, as autoras apresentam o panorama desse fenômeno conforme as regiões brasileiras.

Em termos percentuais, os dados obtidos por Costa e Isquerdo (2010), revelam que a variante carapanã tem 100\% de produtividade na Região Norte do Brasil. Essa nomenclatura, remanescente da base indígena muito presente na região, se mostra como a mais produtiva nas capitais do Norte, e as demais opções não chegam a contabilizar 1\% de ocorrência. As variantes esperadas, que seriam pernilongo e mosquito, são mais constantes nas regiões Sul e Sudeste. A dissertação de Sá (2013) também demonstrou a exclusividade da variante carapanã no distrito de Mosqueiro, estado

${ }^{5}$ As figurinhas que expressam emoções muito utilizadas em aplicativos de troca de mensagens.

https://periodicos.unifap.br/index.php/letras

Macapá, v. 10, n. 1, $1^{\circ}$ sem., 2020 
do Pará.

Ao compararem os dados do Atlas Léxico-Sonoro do Pará - ALeSPA, representativos de cidades não-capitais do Estado, a esses resultados obtidos por Costa e Isquerdo (2010) para as capitais brasileiras, Razky, Gomes e Guedes (2012, p. 1402-1403) concluem que:

[...] os dados do ALiB nas capitais brasileiras dão uma visão mais ampla da variação, demonstrando, por exemplo, que a variante "carapanã", de matriz tupi-guarani, é característica não somente no Estado do Pará, mas de toda a região amazônica. Por outro lado, os dados do ALeSPA trazem uma visão mais específica sobre o fenômeno da variação deste item lexical no português falado no Pará, uma vez que demonstram a distribuição das diversas lexias registradas pelo território paraense.

Também na Região Norte, o estudo de Sanches (2015) evidencia a maior frequência de carapanã em dados do Amapá, outro estado que faz fronteira com o Pará.

Ainda em relação à Questão 88 do QSL/ALiB, os dados de Barbosa e Isquerdo (2017) comprovam a fala do personagem-pai acerca do fato de que, em Belém, se diz carapanã. As autoras mostram que, na capital paraense, a unidade lexical carapanã é a mais produtiva no Norte do país, o que significa dizer Acre, Amazonas, Amapá, Roraima, Rondônia e Pará. Esses dados “[...] confirmam o uso generalizado da variante carapanã que se consolida como particularidade regional do falar amazônico" (NASCENTES, 1953, p. 253). Dentre as variantes encontradas no vídeo, essa é a que o personagem central se refere com mais veemência como própria do estado do Pará. Como vimos, a internet favorece a disseminação da informação, mas também é palco para a manifestação de atos que envolvem o sentimento de pertencimento e origem, como é o caso da ideia central do vídeo analisado.

Curiosamente, no diálogo do vídeo, o pai, diante da resposta insistente de Kevenzinho de que o nome daquele inseto seria mosquito, já que era assim que estava escrito na embalagem do spray de veneno, apontado pelo próprio garoto, justifica que o produto contém esse nome porque é feito, segundo ele, no Sul do Brasil. Para sustentar seu ponto de vista em favor da variante carapanã, Bob Flly recorre a aspectos extralinguísticos, como hábitos culturais e traços da culinária, perguntando a seu filho se ele (o pai) está no Sul, todo empacotado com jaqueta, agasalho, colocando granola no açaí, falando porta com o erre enrolado (retroflexo), etc. Diante desse conjunto de elementos, Kevenzinho parece se convencer de que realmente no Pará se diz carapanã.

Em continuidade, encontramos ainda estudos que registram resultados para a Questão 32, desta vez no Questionário Fonético-Fonológico - QFF/ALiB ... aquilo que dá no chão, grande (mímica), com uma casca grossa vermelho-amarelada por dentro e que se cozinha para comer, fazer bolo? para a qual se espera a resposta abóbora, variante dada pelo personagem Kevenzinho, contrariando a expectativa de seu pai, que logo o corrige dizendo que se trata de jerimum. A investigação de Nelo, Queiroz e Gonçalves (2019), comprova que, na região Norte, jerimum é a variante mais usual. Os resultados referentes a jerimum no Norte brasileiro mostram que essa variante é a mais produtiva na fala dos colaboradores investigados, mesmo que abóbora seja a opção difundida pela escola. Além disso, assim como carapanã, esse termo também tem origem indígena, testemunhando a influência dos povos tradicionais que ajudaram na constituição da população dessa região.

Outro exemplo de variação lexical presente na aula em questão se refere à pergunta sobre o nome do animal ilustrado por uma rã. Para Kevenzinho, esse animal se chama perereca, mas seu pai o corrige, dizendo que aquilo se denomina jia. Embora não tenhamos achado estudo linguístico que registre essa variação, os dicionários Houaiss (2009) e Michaelis online consideram esses itens lexicais como sinônimos, no campo semântico da zoologia.

Por fim, encontramos um exemplo de variação semântica, em que uma forma linguística apresenta mais de um significado socialmente elaborado pela comunidade. Assim, diante da mesma pergunta sobre o nome do animal ilustrado por uma rãa, Kevenzinho responde perereca, recebendo

https://periodicos.unifap.br/index.php/letras

Macapá, v. 10, n. 1, $1^{\circ}$ sem., 2020 
em seguida a reprovação do pai, dizendo que se trata de outra coisa suspostamente do universo dos adultos. No intervalo do vídeo 02: 27 - 02: em que o personagem-pai indica ao filho "- Perereca pra cá é outra coisa, mas tu tá muito jovem pra essa conversa (risos)", percebemos que ele claramente aciona a competência de uso, dando a entender que, no Pará, entre pessoas adultas, perereca se refere também ao órgão genital feminino, significado

reconhecível por grande parte do público que o assiste, porém, a criança não acompanha o sentido, pois, tendo em vista sua idade, ainda não compartilha dos elementos necessários ao entendimento da fala do pai. Até a conclusão deste artigo, não encontramos nenhum trabalho científico de descrição linguística, com dados paraenses, que tenha registrado essa variação semântica, mas ambos os dicionários acima mencionados relacionam perereca à vulva, marcando tal acepção no contexto informal e de sentido jocoso.

Os resultados mostram que, para além do humor, marca característica dos vídeos do digital influencer Bob Flly, os vídeos apresentam ainda um vínculo identitário elevado, o que pode ser confirmado até pelos títulos que são dados a cada produção do autor. Ademais, a união desses dois fatores (humor e identidade) ao aspecto diatópico revelou escalas de variação em três níveis. O que aparentemente anuncia o riso, a distração, carrega também marcas profundas da identidade, as quais são arroladas ao longo da vida, na maioria das vezes por conta da localização do falante, da cultura local e do convívio em grupo.

\section{CONSIDERAÇÕES FINAIS}

A motivação inicial para a elaboração deste artigo surgiu a partir da visualização do vídeo intitulado Estudos Paraenses, distribuído pelo youtuber Bob Flly. Nessa mídia audiovisual, o autor apresenta dois personagens centrais, pai e filho, os quais simulam a realização de uma atividade escolar em casa. Devido ao período da pandemia do novo Coronavírus (Covid-19), no ano de 2020, os pais passaram a representar a figura de educador ou professor no auxílio dado aos filhos. Dessa relação, emana o objeto de nossa investigação: as falas regionalizadas, carregadas de humor e traços de identidade que o personagem-pai enfatiza em seu discurso.

Para realizarmos essa tarefa, analisamos o vídeo e selecionamos as lexias postas em evidência. Nesse processo, foram encontrados seis exemplos de unidades lexicais: lagartixa, libélula, galinha d'angola, lowva-a-deus, ponhamesa e mosquito. Partindo desses arquétipos, verificamos três tipos principais de variação: lexical, fonética e semântica. No contexto geral, comparamos a fala do personagem com estudos científicos realizados sobre o mesmo tema, para o qual encontramos estudos de cunho geolinguísticos e geossociolinguísticos.

Acerca do processo que envolve a distribuição das variantes por região brasileira, vimos que, para perereca e jia, não identificamos trabalhos sobre esses itens lexicais nas bases pesquisadas. Em contrapartida, todos os demais foram registrados, como libélula, galinha d'angola e mosquito, que já foram objeto de estudo.

Dentre os resultados mais expressivos, é possível afirmar que a maneira humorística como o youtuber propaga as variantes paraenses possibilitam a ele a difusão de seu trabalho, sobretudo o fato de ficar famoso nas redes sociais, porém, não se pode deixar de destacar como a noção de identidade por ele assumida frente às diferentes manifestações da língua operam para que ele obtenha êxito em sua empreitada sempre bem-humorada.

O modo particular como os internautas recebem o conteúdo difundido por Bob Flly está atrelado, dentre outras características, à particularidade expressa em seu discurso, ao apelo regional das falas pontualmente encaixadas, elementos que atribuem sensação de coletividade, identidade, mesmo quando o veículo que dissemina essa mídia é o ambiente virtual.

Deste modo, mesmo de maneira inconsciente, Bob Flly arrola em seu vídeo Estudos Paraenses as mesmas lexias, as quais são as mais produtivas encontradas também em estudos científicos de natureza geolinguística e geossociolinguística, o que lhe permite afirmar que sim, no Pará, se diz jacinta, picota e claro, carapanã! 


\section{REFERÊNCIAS}

AGUILERA, V. de A. De onde vieram e por onde andam as nossas libélulas e jacintas? um estudo da etimologia popular com base em dados do Atlas Linguístico do Brasil (ALiB). Estudos Lingüísticos e Literários, n. 41, Salvador, 2010.

AGUILERA, V. de A.; ARAGÃO, M. do S.; ISQUERDO, A. N.; MOTA, J. A.; "Variação Fônica e Léxico-semântica no Português do Brasil a partir de Dados do Projeto ALiB", p. 73 -96. In: Rumos da linguística brasileira no século XXI. São Paulo: Blucher, 2016.

ALKMIN, T. Sociolinguística: parte I. In: MUSSALIM, F.; BENTES, A. C. (orgs.). Introdução à linguística: domínios e fronteiras. 9. ed. São Paulo: Cortez, 2012, p. 23-50, v. 1.

BARBOSA, T. F. M.; ISQUERDO, A. N. Um estudo no campo léxico da fauna nas Regiões Norte e Sul do Brasil: o caso do pernilongo. In: Anais do IXI SINEFIL. Rio de Janeiro: CiFEFiL, jan./abr.2017.

BARROS, C. P. O falar do "caboco" paraense: um estudo sobre o léxico nos municípios de Santarém, Oriximiná e Juruti (Baixo-Amazonas- PA). 2017. 213f. Dissertação (Mestrado em Letras) - Universidade Federal do Amazonas, Manaus, 2017.

BERGSON, H. O Riso. Ensaio sobre a significação do cômico. $2^{\circ}$ Ed. Rio de Janeiro, Zahar, 1983. BORTONI-RICARDO, S. M. Manual de sociolinguistica. São Paulo: Contexto, 2014.

CARDOSO, A. M.; MOTA, J. A. Projeto atlas linguístico do Brasil: antecedentes e estágio atual. Alfa, São Paulo, 56 (3): 855-870, 2012. Disponível em: https://www.scielo.br/pdf/alfa/v56n3/a06v56n3.pdf. Acesso em: 30 set. 2020.

COSTA, D. S. S.; ISQUERDO, A. N. Denominações para "pernilongo" nas capitais brasileiras: um estudo geolinguístico e léxico-semântico. In: Revista Travessias. Pesquisas em Educação, Cultura, Linguagens e Artes. n. 3, Vol. 4, 2010.

COSTA, S. S. de Oliveira; SILVA, M. P. S. C. Cartografia linguística: um estudo semântico-lexical da fala dos moradores do município de Igarapé-miri/PA. Ribanceira. Revista de Letras da Universidade do Estado do Pará -UEPA. n. 15, out-dez 2018.

FLLY, B. Aulas de estudos paraenses. Canal Pavulagem. 2020. (03m04s). Disponível em: https://www.youtube.com/watch?v=uxxEOsrU6Fs. Acesso em 01 de agosto de 2020.

FREUD, S. O chiste e sua relação com o inconsciente [1905]. Rio de Janeiro: Imago, 1977.

GUEDES, R. J. da C. Estudo Geossociolinguístico da variação lexical na zona rural do estado do Pará. 2012. 165f. Dissertação de Mestrado -Instituto de Letras e Comunicação. Universidade Federal do Pará, Belém, 2012.

GUY, G. R. Rumos da Sociodialetologia da América latina. In: Congresso Internacional de Dialetologia e Sociolinguística (2: 2012: Belém, PA). Diversidade linguística e políticas de ensino: anais. São Luís: EDUFMA, 2012.

HOUAISS, A. Dicionário eletrônico Houaiss da língua portuguesa. Rio de Janeiro: Objetiva.Versão3.0,2009.

LABOV, W. Padrões sociolinguísticos. Trad. de M. Bagno; M. M. P. Scherre; C. R. Cardoso. São Paulo: Parábola Editorial, 2008 [1972].

LÉVY, P. Cibercultura. 3 ed. Tradução de Carlos Irineu da Costa São Paulo: Editora 34, 2010.

LÉVY, P. O que é o virtual? 2 ed. Tradução de Paulo Neves. São Paulo: Editora 34, 2011.

LIMA, A. F.; RAZKY, A.; OLIVEIRA, M. B. O. A metodologia geossociolinguística. In: RAZKY, A.; OLIVEIRA, M. B. O.; LIMA, A. F. (Orgs.). Estudos Geossociolinguisticos do Português Brasileiro. V. 2. Campinas, SP: Pontes Editores, 2020, p. 11-48.

LUCCHESI, D. Lingua e sociedade partidas: a polarização sociolinguística do Brasil. São Paulo: Contexto, 2015.

MOLLICA, M. C. Fundamentação teórica: conceituação e delimitação. In: MOLLICA, M. C.; BRAGA, M. L. Introdução à sociolinguística: o tratamento da variação. 4 ed. São Paulo: Contexto, 2015. NASCENTES, A. O linguajar carioca. Rio de Janeiro: Organização Simões, 1953.

NELO, M. J.; QUEIROZ, N. da S.; GONÇALVES, G. S. Abóbora ou Jerimum? Um Estudo

https://periodicos.unifap.br/index.php/letras

Macapá, v. 10, n. 1, $1^{\circ}$ sem., 2020 
Semântico Lexical. In: Revista Latinoamericana de Estudios en Culturay Sociedad. Latin American Journal of Studies in Culture and Society V. 05, no 02, abr-ago., 2019, artigo $\mathrm{n}^{\circ} 1629$.

POSSENTI, S. Os humores da língua: análises linguísticas de piadas. Campinas, SP Mercado de Letras, p.152, 1998.

RAJAGOPALAN, K. O conceito de identidade em linguística: é chegada a hora para uma reconsideração radical? In: SIGNORINI, Inês (org.). "Lingua(gem) e Identidade: elementos para uma discussão no campo aplicado" Campinas: Mercado das Letras. São Paulo: Fapesp, 1998. RAJAGOPALAN, K. Por uma lingüistica crítica: linguagem, identidade e questão ética. Sâo Paulo: Parábola Editorial, 2003.

RAMOS, C. de M. de A.; BEZERRA, J. de R. M; ROCHA, M. de F.; REIS, M. R. No céu do Maranhão, cruzam-se catirinas, tingas e pragas: um estudo semântico-lexical da fauna maranhense. In: Cardoso, Suzana Alice Marcelino. Documentos 3: projeto atlas linguístico do Brasil / Suzana Alice Marcelino Cardoso; Jacyra Andrade Mota; Marcela Moura Torres Paim (Orgs.). Salvador: Vento Leste, 2012.

RAZKY, A.; CARDOSO, S. A. M. O Atlas Geossociolinguístico do Pará: o projeto piloto. Moara - Revista do Programa de Pós-graduação em Letras da UFPA. v. 4. Belém, p. 47-58, 1997.

RAZKY, A. O Atlas geossociolinguístico do Pará: Abordagem metodológica. In: AGUILERA, Vanderci de Andrade. (Org.). A Geolingüistica no Brasil: caminhos e perspectivas. Londrina: UEL, 1998.

RAZKY, A.; GOMES, E. F.; GUEDES, R. J. da Cunha. Variação lexical na mesorregião sudeste do Pará: um olhar sobre os dados do atlas léxico sonoro do Pará - ALeSPA. Revista Philologus, Ano 23, n. 67, Rio de Janeiro: CiFEFiL, jan./abr.2017.

SANCHES, R. V ariação lexical nos dados do projeto atlas geossociolinguístico do Amapá. 2015. 165f. Dissertação (Mestrado em Letras) - Universidade Federal do Pará, Belém, 2015.

SÁ, E. J. de. Atlas linguístico de Pernambuco: da metodologia aos resultados. In: XVII Congresso Internacional da ALFAL, 2014, Rio de Janeiro. Estudos Linguísticos e Filológicos. João Pessoa - PB: Editora Ideia, 2014. v. 1.

SÁ, T. R. de. Pelos caminhos da geolinguística paraense: um estudo do léxico do Distrito de Mosqueiro numa perspectiva socioeducacional. Dissertação de Mestrado. 282f. Universidade do Estado do Pará, 2013.

SPOLSKY, B. Sociolinguistics. Oxford: Oxford University Press, 1998.

TARALLO, F. A pesquisa sociolinguística. 8 ed. São Paulo: Ática, 2007.

WEINREICH, U.; LABOV, W.; HERZOG, M. Fundamentos empiricos para uma teoria da mudança linguística. Tradução Marcos Bagno. São Paulo: Parábola Editorial, 2006 [1968].

YIN, R. K. Estudo de caso: planejamento e métodos. 4. ed. Porto Alegre: Bookman, 2018. 